University of Nebraska - Lincoln

DigitalCommons@University of Nebraska - Lincoln

USDA National Wildlife Research Center - Staff Publications
U.S. Department of Agriculture: Animal and Plant Health Inspection Service

2012

\title{
Crow Pellets from Winter Roosts in Lancaster, Pennsylvania
}

\author{
Mary Annala \\ Michigan Technological University, mkannala@mtu.edu \\ Eric A. Tillman \\ USDA/APHIS/WS National Wildlife Research Center, eric.a.tillmann@aphis.usda.gov \\ Gregory A. Backus \\ Bard College, gabackus@ncsu.edu \\ Kandy L. Keacher \\ United States Department of Agriculture, kandy.I.keacher@aphis.usda.gov \\ Michael L. Avery \\ USDA/APHIS/WS National Wildlife Research Center, michael.I.avery@aphis.usda.gov
}

Follow this and additional works at: https://digitalcommons.unl.edu/icwdm_usdanwrc

Annala, Mary; Tillman, Eric A.; Backus, Gregory A.; Keacher, Kandy L.; and Avery, Michael L., "Crow Pellets from Winter Roosts in Lancaster, Pennsylvania" (2012). USDA National Wildlife Research Center - Staff Publications. 1092.

https://digitalcommons.unl.edu/icwdm_usdanwrc/1092

This Article is brought to you for free and open access by the U.S. Department of Agriculture: Animal and Plant Health Inspection Service at DigitalCommons@University of Nebraska - Lincoln. It has been accepted for inclusion in USDA National Wildlife Research Center - Staff Publications by an authorized administrator of DigitalCommons@University of Nebraska - Lincoln. 


\title{
Crow Pellets from Winter Roosts in Lancaster, Pennsylvania
}

\author{
Mary Annala ${ }^{1}$, Eric A. Tillman ${ }^{2}$, Gregory Backus ${ }^{3}$, Kandy L. Keacher ${ }^{2}$, \\ and Michael L. Avery,"*
}

\begin{abstract}
Although crows cast pellets, there is little quantitative information on pellets from Corvus brachyrhynchos (American Crow), and none from C. ossifragus (Fish Crow). During a study of crow roost dispersal in Lancaster, PA, we collected samples of pellets from several locations. By mass, pellets consisted mostly of grit and other fine inorganic material, various seeds (principally Toxicodendron radicans [Poison Ivy] and Celtis occidentalis [Common Hackberry]), and vegetation remnants. Six pellets contained small-mammal bones. Because the Lancaster winter crow population included many Fish Crows, the source of the pellets was not certain. To clarify this, we compared the size of the Lancaster crow pellets to those produced by captive Fish Crows, and we provide the first quantitative description of pellets for either species. Our size comparisons suggest that $>90 \%$ of the pellets in our sample from Lancaster were produced by American Crows.
\end{abstract}

\section{Introduction}

Pellet-casting has been reported within at least 18 orders of birds (Below 1979). Pellets usually contain indigestible parts of prey items, so pellet analysis is a standard means for studying avian food habits (Coleman and Fraser 1987, Errington 1932, Glading et al. 1943). Among passerines, Corvus spp. (crows) regularly produce pellets (Berrow et al. 1992, Dean and Milton 2000, Kurosawa et al. 2003).

Barrows and Schwarz (1895) described pellet production in Corvus brachyrhynchos Brehm (American Crow). They provided a sketch of a typical crow pellet, but included no measurements, nor did they characterize crow pellet contents except in a general way. We are aware of just two additional studies of crow pellets in the USA. Black (1941) collected 1214 pellets from 12 winter American Crow roosts in Illinois, but he combined all pellets from each site for analysis. Major food items identified by Black (1941) included corn, various common weed seeds, and small mammals (bones or teeth occurred in 178 pellets). He estimated that grit comprised $17.6 \%$ of the pellets, by volume. Platt (1956) collected 617 American Crow pellets year-round in south-central Kansas and examined them singly, although he quantified only the food items, "excluding sand and other extraneous material", and he provided no

${ }^{1}$ Department of Wildlife Ecology, Michigan Technological University, Houghton, MI 49931. ${ }^{2}$ United States Department of Agriculture, Wildlife Services, National Wildlife Research Center, 2820 East University Avenue, Gainesville, FL 32641. ${ }^{3}$ Department of Biology, Bard College, Annandale-on-Hudson, NY 12504. " Corresponding author michael.1.avery@aphis.usda.gov.

This article is a U.S. government work, and is not subject to copyright in the United States. 
measurements of pellet size. Field crops (wheat, sorghum, oats, sunflower, and corn) comprised $59 \%$ of the identifiable food residues, invertebrates comprised $26.5 \%$, and mammal remains 2.6\% (Platt 1956). Apparently, published information on pellets from Corvus ossifragus Wilson (Fish Crow) is lacking (McGowan 2001).

While conducting a study of winter crow roost dispersal, we noticed large numbers of pellets at several locations in the Lancaster, PA area. This roosting crow population consisted of 30,000-40,000 birds, including both Fish and American crows (Avery et al. 2008). Because quantitative information on crow pellets is scarce, particularly regarding the Fish Crow, we collected and analyzed pellets to understand more about this phenomenon. Further, to separate pellets according to species origin, we compared the Pennsylvania field sample to pellets produced by captive Fish Crows in Florida.

\section{Methods}

We opportunistically collected 113 crow pellets from locations throughout Lancaster, PA during November-January 2005 and 2006. The locations included a parking garage, various roads and lawns, and a vacant warehouse. For each pellet, we recorded location and date of collection, placed them individually in plastic bags, and froze them for later analysis.

We measured length and width of intact pellets using digital calipers. We placed the pellets in a drying oven for 2-4 hours and then we weighed each pellet on a digital balance. To determine the composition of the pellets, each pellet was crushed and sifted through a series of sieves (US Standard Sieve Series with ASTM specifications). We used level 4 with a 4.75-mm (0.19-in) mesh, level 6 with a 3.35-mm (0.13-in) mesh, level 12 with a $1.68-\mathrm{mm}(0.07-\mathrm{in}) \mathrm{mesh}$, and level 18 with a $1.00-\mathrm{mm}(0.04-\mathrm{in}) \mathrm{mesh}$. For each pellet, we separated material caught in each sieve into categories of Grit, Seeds, Vegetation, and Other. For sieve levels 4, 6, and 12, we counted the individual pieces in each category and then weighed each category in aggregate. The materials in level 18 and the bottom collection pan were too fine to be counted individually, so only the total mass was recorded. We assessed differences among collection sites in mass, length, width, and composition of the pellets using one-way analyses of variance.

In Gainesville, FL, we maintained 7 Fish Crows in 2 outdoor group pens $(3.1 \mathrm{x}$ $9.3 \times 1.7 \mathrm{~m})$. Mean body mass of these crows $(281 \mathrm{~g}, \mathrm{SE}=7, n=7)$ did not differ $\left(F_{1,60}=0.53, P=0.468\right)$ from that of the Fish Crows we trapped in Lancaster, PA ( $288 \mathrm{~g}, \mathrm{SE}=3, n=55$ ). The birds received a diet of cracked corn, chopped fruit, and commercial dry dog food, as well as grit and sand. During April-June 2011, we collected intact pellets opportunistically and measured their length and width, but did not deconstruct them. We compared the measurements of Fish Crow pellets with the field sample using one-way analyses of variance. 


\section{Results}

\section{Pellet composition}

Among the Pennsylvania pellets, grit comprised almost half of the mass of all pellets, while $35 \%$ consisted of fine materials too small to identify in the bottomlayer collection pan. Vegetation remnants including corn seed fragments, bits of stems, and ground-up leaf material comprised $6 \%$ of the pellet mass. Weed seeds were very abundant in pellets from two sites and comprised $8 \%$ of the pellet composition overall. The most common seed was Toxicodendron radicans $\mathrm{L}$. Kuntze (Poison Ivy). These seeds averaged $10 \mathrm{mg}$, with mean length of $4.5 \mathrm{~mm}$ and mean width of $2.9 \mathrm{~mm}$. The only other identified seed was Celtis occidentalis L. (Common Hackberry), which averaged $6.1 \mathrm{~mm}$ in diameter with mean mass of $0.1 \mathrm{~g}$. The "other" category included teeth and bone fragments from small mammals $(n=6$ pellets) and one piece of rubber $(n=1$ pellet $)$.

\section{Pellet size}

The mean width of pellets from the Pennsylvania field sample $(16.9 \mathrm{~mm}$, $\mathrm{SE}=0.2, n=113)$ exceeded $\left(F_{1,158}=347.51, P<0.001\right)$ that of the captive Fish Crows $(11.6 \mathrm{~mm}, \mathrm{SE}=0.2, n=46)$. The mean length of pellets from the field sample $(32.6 \mathrm{~mm}, \mathrm{SE}=0.5, n=113)$ also exceeded $\left(F_{1,158}=135.25, P<0.001\right)$ that of pellets produced by the captive Fish Crows $(21.5 \mathrm{~mm}, \mathrm{SE}=0.7, n=$ 46). There was very little overlap in the width distributions of the two samples (Fig. 1). Thus, based on the width dimension, it appears that only 11 of the 113 (9.7\%) pellets collected in Lancaster were small enough to be within the size range of those produced by Fish Crows. The composition of these 11 pellets did not differ from the 102 larger pellets in percent grit $(P=0.754)$, seeds $(P=$

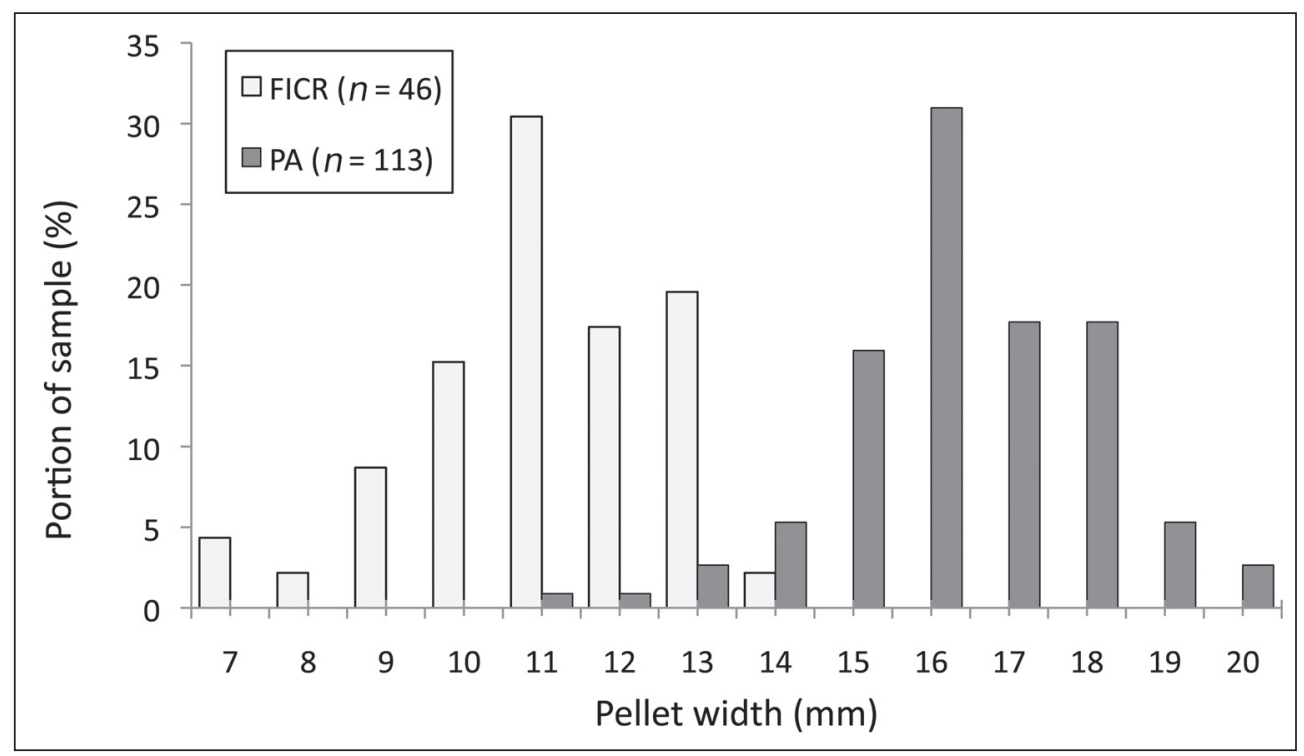

Figure 1. Distribution of crow pellet widths collected from Lancaster, PA $(n=113)$ and produced by captive Fish Crows (FICR) in Gainesville, FL $(n=46)$. 
0.661), or vegetation remnants $(P=0.412)$. Except for their respective sizes, the pellets from Pennsylvania and Florida were very similar in appearance (Fig. 2).

\section{Discussion}

The paucity of quantitative information on crow pellets can be ascribed to seasonality and fragility. Foods taken during the non-breeding season, particularly waste corn, are often hard and difficult to digest, necessitating intake of grit and sand, which comprise the bulk of the pellets. During other months, soft fruit, insects, and other more readily digestible items dominate the diet, presumably lessening the need for digestive aids. Platt (1956) noted that the availability of crow pellets diminished outside the winter season.

In Lancaster, crows often staged or roosted on lawns, parking lots, and roofs (Avery et al. 2008). Thus, at these sites disgorged pellets did not fall far and therefore many remained intact. The chance of pellets produced by crows in tree roosts surviving intact is greatly diminished (Barrows and Schwarz 1895). Furthermore, crow pellets are not weather-resistant. Unless collected the day after being deposited, the likelihood of finding a pellet intact is greatly reduced.

Direct comparisons of the composition of pellets we collected in Pennsylvania with those reported previously by Black (1941) in Illinois and Platt (1956) in Kansas are difficult because of differences in collecting, analyzing, and reporting. We can say that grit was a predominant constituent in each sample, that the bulk of the food items were vegetation, and that weed seeds (including Poison Ivy and Common Hackberry) were common. Bones and teeth of small mammals occurred in 5\% of the pellets in our sample compared to $15 \%$ in Illinois and $12 \%$ in Kansas. Unlike the samples from Illinois and Pennsylvania, which contained corn remnants, the Kansas pellet sample included a wide variety of crop seeds, reflecting differences in what was locally available to wintering crows.

In comparing dietary information derived from pellets versus stomach contents, Black (1941) noted consistent similarity. The usefulness of pellets will likely depend on the questions being investigated. For food-habit studies, crow

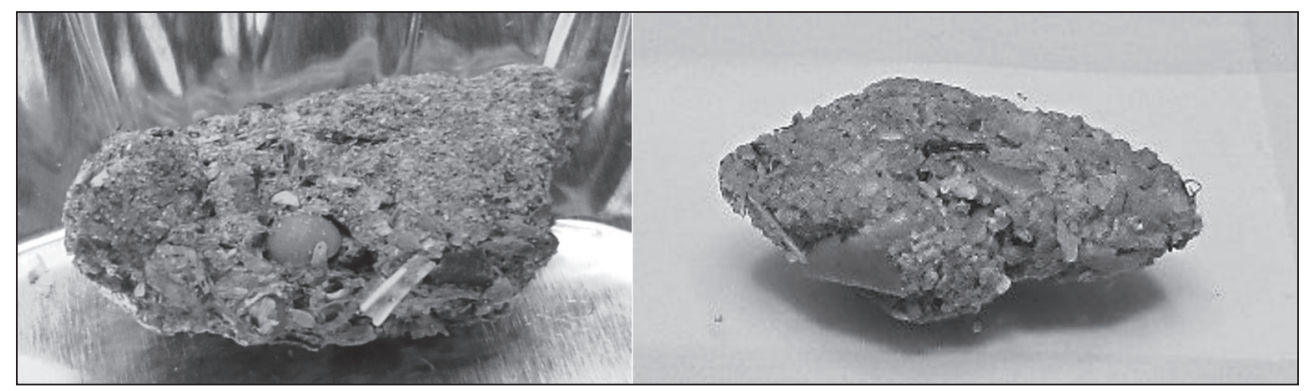

Figure 2. Crow pellet collected in Lancaster, PA (left; $31.1 \mathrm{~mm}$ long x $16.9 \mathrm{~mm}$ wide) and pellet produced by captive Fish Crow in Gainesville, FL (right; $25.6 \mathrm{~mm}$ long x 12.8 mm wide). 
pellets have an obvious advantage in that large samples can be obtained without killing any birds, and repeated sampling at a given roost site can provide a temporal view of the food habits of the population (e.g., Platt 1956). There are several limitations, however. For example, the specific foraging site cannot be known, so it is not possible to relate the pellet contents to food availability; pellets largely consist of grit and other non-food material; and as in our case, the species that produced the pellet is not always known.

The winter crow population in Lancaster, PA consists of Fish and American Crows. The percent species composition is not known and several lines of evidence produce disparate estimates. During our study, we captured 601 Fish Crows in modified Australian crow traps compared to 46 American Crows (Avery et al. 2008). Cannon-netting yielded 10 Fish Crows and 4 American Crows. Conversely, counts of calls from crows exiting Lancaster roosts in the morning suggested approximately 90\% were American Crows (M. Brittingham, Pennsylvania State University, State College, PA, unpubl. data). Recent Christmas Bird Count results indicate $>90 \%$ of the Lancaster area crows were American Crows (http://audubon2.org/cbchist/count_table.html).

Based on the size distribution of the pellets produced by the captive Fish Crows relative to our field sample, we conclude that the vast majority of the pellets we collected from Lancaster were produced by American Crows. Whether or not this reflects the actual species composition of the winter crow population in the Lancaster area is unknown.

\section{Acknowledgments}

Support was provided by the Berryman Institute, Mississippi State University (M. Annala and G. Backus), and by the National Wildlife Research Center (E.A. Tillman, K.L. Keacher, and M.L. Avery). W.E. Bruce assisted with animal care.

\section{Literature Cited}

Avery, M.L., E.A. Tillman, and J.S. Humphrey. 2008. Effigies for dispersing urban crow roosts. Vertebrate Pest Conference 23:84-87.

Barrows, W.B., and E.A. Schwarz. 1895. The Common Crow of the United States. Bulletin 6, Division of Ornithology and Mammalogy, US Department of Agriculture. Washington, DC.

Below, T.H. 1979. First reports of pellet ejection in 11 species. Wilson Bulletin 91:626-628.

Berrow, S.D., T.C. Kelly, and A.A. Myers. 1992. The diet of coastal breeding Hooded Crows, Corvus corone comix. Ecography 15:337-346.

Black, C.T. 1941. Ecological and economic relations of the crow, with special reference to Illinois. Ph.D. Thesis, University of Illinois, Urbana, IL.

Coleman, J.S., and J.D. Fraser. 1987. Food habits of Black and Turkey Vultures in Pennsylvania and Maryland. Journal of Wildlife Management 51:733-739.

Dean, W.R.J., and S.J. Milton. 2000. Directed dispersal of Opuntia species in the Karoo, South Africa: Are crows the responsible agents? Journal of Arid Environments 45:305-314. 
Errington, P.L. 1932. Technique of raptor food habits study. Condor 34:75-86.

Glading, B., D.F. Tillotson, and D.M. Selleck. 1943. Raptor pellets as indicators of food habits. California Fish and Game 29:92-121.

Kurosawa, R., R. Kono, T. Kondo, and Y. Kanai. 2003. Diet of Jungle Crows in an urban landscape. Global Environmental Research 7:193-198.

McGowan, K.J. 2001. Fish Crow (Corvus ossifragus). In A. Poole and F. Gill (Eds.). The Birds of North America. No. 589. The Birds of North America, Philadelphia, PA.

Platt, D. 1956. Food of the crow, Corvus brachyrhynchos Brehm, in south-central Kansas. University of Kansas Publications, Museum of Natural History 8:477-498. 